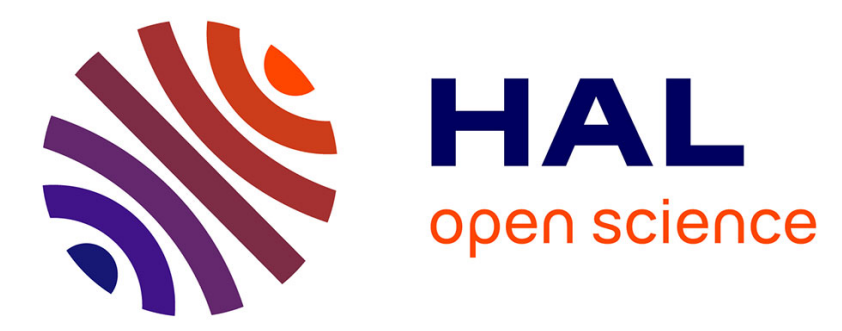

\title{
Evaluating the maximum domain of parameter model uncertainties in the combustion of a Diesel engine
}

\author{
Mihaela-Ancuta Mone, Sette Diop, Dumitru Popescu
}

\section{To cite this version:}

Mihaela-Ancuta Mone, Sette Diop, Dumitru Popescu. Evaluating the maximum domain of parameter model uncertainties in the combustion of a Diesel engine. 2021 25th International Conference on System Theory, Control and Computing (ICSTCC), Oct 2021, Iasi, Romania. pp.12-17, 10.1109/ICSTCC52150.2021.9607091. hal-03448410

\section{HAL Id: hal-03448410}

\section{https://hal-centralesupelec.archives-ouvertes.fr/hal-03448410}

Submitted on 26 Nov 2021

HAL is a multi-disciplinary open access archive for the deposit and dissemination of scientific research documents, whether they are published or not. The documents may come from teaching and research institutions in France or abroad, or from public or private research centers.
L'archive ouverte pluridisciplinaire HAL, est destinée au dépôt et à la diffusion de documents scientifiques de niveau recherche, publiés ou non, émanant des établissements d'enseignement et de recherche français ou étrangers, des laboratoires publics ou privés. 


\section{Evaluating the maximum domain of parameter model uncertainties in the combustion of a Diesel engine}

\author{
Mihaela-Ancuța Mone \\ Systems Engineering \\ Faculty of Automatic Control and \\ Computers \\ Bucharest, Romania \\ mihaela mone@stud.acs.upb ro
}

\author{
Sette Diop \\ Laboratoire des signaux et systèmes \\ CentraleSupélec, Université Paris- \\ Saclay \\ Gif-sur-Yvette, France \\ sette.diop@12s.centralesupelec fr
}

\author{
Dumitru Popescu \\ Systems Engineering \\ Faculty of Automatic Control and \\ Computers \\ Bucharest, Romania \\ dumitru.popescu@acse.upbro
}

\begin{abstract}
This paper proposes a LQR control algorithm and a robustness stability analysis to the model parameter uncertainties so that the mass air flow and the manifold absolute pressure of an experimental Diesel engine can be performed. The corresponding weight matrices of the LQR control are chosen based on the maximum admissible deviation values of the state matrices and command vector from the state-space system representation. This approach leads to finding the maximum upper bounds of the model parameter uncertainties so that the closed-loop system preserves its stability.
\end{abstract}

Keywords-Diesel engine combustion, state-space model representation, LQR control, parameter model uncertainties, robust stability analysis

\section{INTRODUCTION}

The object of our work is to propose some improvements from control solutions based on estimation of model parameter uncertainties on an experimental Diesel engine which is equipped with an Exhaust Gas Recirculation system (EGR) and a Variable Geometry Turbocharger (VGT). Being a model of the internal combustion engine, we want to develop control laws which will help at optimizing the combustion regime of the engine so that the amount of pollutants and fuel consumption are reduced.

The robust stability literature has been populated the past four decades with papers providing the bounds of parameter variations under unstructured perturbations. Reference [1] gives the bounds with respect to the robust stability for a system - whose form is a state-space representation - as the inverse of the maximum singular value of the solution of a Lyapunov function. This approach was applicable for the linear state feedback control of a drone's lateral altitude [2], [3]. Many other authors also focus on the applicability of this solution to aerospace flight control [4-6].

The novelty of the paper consists in the robustness' analysis with respect to parameter uncertainties in the statespace representation of the engine's combustion model and proposes a mix of structures for the corresponding weighting matrices of the LQR controller. This paper is evaluating the maximum bounds of parameter variations which preserve the stability of the closed-loop system in LQR control.

This paper is organized as follows. Section II presents the mathematical models corresponding to the Diesel engine. Section III presents the analysis on the allowable parameter variations for the models presented in Section II, and proposes a new structure of the weight matrices in the LQR control.
Section IV contains the simulation results. Conclusions and perspectives are given in Section V.

\section{Engine's Mathematical Models}

\section{A. Linear parameter varying model}

The combustion regime of any internal combustion engine is characterized by a nonlinear process. First, we estimate the linear-parameter varying class of associated models, whose gain matrices depend on an exogenous parameter, time variant, $w(t)$.

$$
\left\{\begin{array}{l}
\dot{\boldsymbol{x}}(t)=\boldsymbol{A}(w(t)) \boldsymbol{x}(t)+\boldsymbol{B}(w(t)) \boldsymbol{u}(t) \\
\boldsymbol{y}(t)=\boldsymbol{C}(w(t)) \boldsymbol{x}(t)+\boldsymbol{D}(w(t)) \boldsymbol{u}(t)
\end{array}\right.
$$

where $\boldsymbol{x}(t)$ represents the states vector, $\boldsymbol{u}(t)$ - the control vector, $\boldsymbol{y}(t)$ - the output vector.

The parameters contained by matrices $\boldsymbol{A}, \boldsymbol{B}, \boldsymbol{C}$ and $\boldsymbol{D}$ have a nonlinear form, therefore we want to obtain an approximate model of reduced order which will be used for the design and implementation of control algorithms.

\section{B. Invariant state-space model}

Reference [7] proposes an invariant state-space model associated to the Diesel engine, starting from the ideal gas equation, writing a differential equation for both the admission and evacuation cycle of the Diesel engine, and considering the dynamics of the power transfer of the compressor delayed by $\theta$ :

$$
\begin{gathered}
\dot{p}_{\text {in }}=\frac{R T_{\text {in }}}{V_{\text {in }}}\left(F_{\text {in }}+F_{E G R}-F_{I M}\right)+\frac{\dot{T}_{\text {in }}}{T_{\text {in }}} p_{\text {in }} \\
\dot{p}_{\text {out }}=\frac{R T_{\text {out }}}{V_{\text {out }}}\left(F_{I M}+F_{F}-F_{E G R}-F_{V G T}\right)+\frac{\dot{T}_{\text {out }}}{T_{\text {out }}} p_{\text {out }} \\
\dot{P}_{C}=\frac{P_{T^{-}-P_{C}}}{\theta}
\end{gathered}
$$

The index in denotes the parameters at intake, out denotes the parameters at exhaust, $p$ is the pressure, $T$ is the temperature, $V$ is the volume, $R$ is the Reynolds constant, $F_{E G R}$ is the flow through the EGR, $F_{V G T}$ is the flow through the VGT, $F_{I M}$ - the flow through the intake manifold, $F_{F}$-the fuel flow, $P_{C}$ - compressor power, $P_{T}$ - turbine power.

By remodeling $F_{V G T}$ and $F_{E G R}$ as the equation of flow through a restriction, and considering the conservation of mass in an open system, (2) can be rewritten as a state-space representation [7], [8]: 


$$
\begin{gathered}
\left(\begin{array}{c}
\dot{p}_{\text {in }} \\
\dot{p}_{\text {out }} \\
\dot{P}_{C}
\end{array}\right)=\boldsymbol{A}\left(\begin{array}{c}
p_{\text {in }} \\
p_{\text {out }} \\
P_{C}
\end{array}\right)+\boldsymbol{B}\left(\begin{array}{c}
S_{E G R} \\
x_{V G T} \\
N \\
F_{F}
\end{array}\right) \\
\left(\begin{array}{c}
F_{\text {in }} \\
p_{\text {in }}
\end{array}\right)=\boldsymbol{C}\left(\begin{array}{c}
p_{\text {in }} \\
p_{\text {out }} \\
P_{C}
\end{array}\right)
\end{gathered}
$$

where the elements of the input vector are $S_{E G R}$ - the surface of the EGR valve, $x_{V G T}-$ the position of the VGT valve, $N-$ the engine speed; the elements of the output vector are $F_{\text {in }}-$ the mass air flow to be controlled and $p_{i n}$ - the manifold absolute pressure to be controlled.

\section{Reduced invariant state-space model}

The inputs $S_{E G R}$ and $x_{V G T}$ are redefined based on the center of the actuator range, the fuel flow and the engine speed are considered constant and the following reduced invariant models is obtained [7]:

$$
\begin{aligned}
\left(\begin{array}{c}
\dot{p}_{\text {in }} \\
\dot{p}_{\text {out }} \\
\dot{P}_{C}
\end{array}\right) & =\boldsymbol{A}^{\prime}\left(\begin{array}{c}
p_{\text {in }} \\
p_{\text {out }} \\
P_{C}
\end{array}\right)+\boldsymbol{B}^{\prime}\left(\begin{array}{c}
S_{E G R} \\
x_{V G T}
\end{array}\right) \\
\left(\begin{array}{c}
F_{\text {in }} \\
p_{\text {in }}
\end{array}\right) & =\boldsymbol{C}^{\prime}\left(\begin{array}{c}
p_{\text {in }} \\
p_{\text {out }} \\
P_{C}
\end{array}\right)
\end{aligned}
$$

\section{BOUNDS OF PARAMETER VARIATIONS FOR LQR} CONTROL

We consider the model of a linear time-invariant continuous system with the following state-space representation:

$$
\left\{\begin{array}{l}
\dot{\boldsymbol{x}}(t)=\boldsymbol{A} \boldsymbol{x}(t)+\boldsymbol{B} \boldsymbol{u}(t) \\
\boldsymbol{y}(t)=\boldsymbol{C} \boldsymbol{x}(t)+\boldsymbol{D} \boldsymbol{u}(t)
\end{array}, \boldsymbol{x}\left(t_{0}\right)=x_{0}\right.
$$

whose notations have the same meaning as in (1).

We assume that the pair $(\boldsymbol{A}, \boldsymbol{B})$ is controllable, and the pair $(\boldsymbol{C}, \boldsymbol{A})$ is observable, based on the parameter values from (4).

Let us consider the following quadratic performance criteria [7-10] whose minimization will allow the design of an optimal algorithm for the control of the mass air flow and the manifold absolute pressure:

$$
J(t)=\int_{0}^{\infty} \boldsymbol{x}^{T}(t) \boldsymbol{Q x}(t)+\boldsymbol{u}(t) \boldsymbol{R} \boldsymbol{u}(t) d t
$$

$\boldsymbol{Q}$ and $\boldsymbol{R}$ are symmetrical and positive definite matrices.

The solution $\boldsymbol{u}(t)$ which minimizes $J\left(x_{0}\right)$ is:

$$
\begin{gathered}
\boldsymbol{u}(t)=-\boldsymbol{K} \boldsymbol{x}(t) \\
\boldsymbol{K}=\boldsymbol{R}^{-1} \boldsymbol{B}^{T} \boldsymbol{P}
\end{gathered}
$$

where $\boldsymbol{P}$ is the solution of the Riccati equation [12]:

$$
\boldsymbol{A}^{T} \boldsymbol{P}+\boldsymbol{P} \boldsymbol{A}-\boldsymbol{P B} \boldsymbol{R}^{-1} \boldsymbol{B}^{T} \boldsymbol{P}+\boldsymbol{Q}=0
$$

- $\quad \dot{V}(\boldsymbol{x})=-\boldsymbol{x}^{T}\left(\boldsymbol{Q}+\boldsymbol{K}^{T} \boldsymbol{R} \boldsymbol{K}\right) \boldsymbol{x}<0$, for $\boldsymbol{x} \neq 0$

The modelling errors $\delta \boldsymbol{A}, \delta \boldsymbol{B}, \delta \boldsymbol{C}$, which affect the matrices $\boldsymbol{A}, \boldsymbol{B}$ and $\boldsymbol{C}$, respectively, are considered. Then, the real process is represented by:

$$
\left\{\begin{array}{c}
\dot{\boldsymbol{x}}(t)=(\boldsymbol{A}+\delta \boldsymbol{A}) \boldsymbol{x}(t)+(\boldsymbol{B}+\boldsymbol{\delta} \boldsymbol{B}) \boldsymbol{u}(t) \\
\boldsymbol{y}(t)=(\boldsymbol{C}+\delta \boldsymbol{C}) \boldsymbol{x}(t)
\end{array}\right.
$$

Given the matrix type bounded uncertain structure [3], we can define the uncertainty domain:

$$
D=\left\{\delta \boldsymbol{A}, \delta \boldsymbol{B}: \delta \boldsymbol{A}^{T} \delta \boldsymbol{A} \leq \gamma_{A} \boldsymbol{Q}_{A} \delta \boldsymbol{B}^{T} \delta \boldsymbol{B} \leq \gamma_{B} \boldsymbol{R}_{\boldsymbol{B}}\right\}
$$

where $\boldsymbol{Q}_{A}$ and $\boldsymbol{R}_{B}$ are symmetrical positive definite matrices, $\gamma_{A}$ and $\gamma_{B}$ are positive scalars.

The problem of interest is to find the maximum values of the scalars $\gamma_{A}$ and $\gamma_{B}$ so that the closed-loop system defined by (9), (10) remains stable given the optimal command in (7) [10], [16].

In order to obtain these values, we have to verify the conditions for which the function $V(\boldsymbol{x})=\boldsymbol{x}^{T} \boldsymbol{P} \boldsymbol{x}$ is a Lyapunov function.

We can define the weight matrices $\boldsymbol{Q}$ and $\boldsymbol{R}$ as:

$$
\begin{aligned}
& \boldsymbol{Q}=\boldsymbol{Q}_{A}+\boldsymbol{Q}^{\prime} \\
& \boldsymbol{R}=\boldsymbol{R}_{B}+\boldsymbol{R}^{\prime}
\end{aligned}
$$

where $\boldsymbol{Q}_{A}$ and $\boldsymbol{R}_{B}$ are the matrices in (10), and $\boldsymbol{Q}^{\prime}$ and $\boldsymbol{R}^{\prime}$ are known symmetrical positive definite matrices.

The theoretical results which offer the sufficient stability conditions so that the closed-loop system (9) is stable given the command (7) are presented in [10]. If we consider $\boldsymbol{Q}$ and $\boldsymbol{R}$ as in (11) and we define the following symmetrical positive definite matrix:

$$
\boldsymbol{\Omega}=\boldsymbol{P}^{-1}\left(\boldsymbol{Q}^{\prime}+\boldsymbol{K}^{T} \boldsymbol{R}^{\prime} \boldsymbol{K}\right) \boldsymbol{P}^{-1}
$$

then the closed-loop system is stable for the uncertainties defined in the domain $D(10)$ which satisfy:

$$
\boldsymbol{\Omega}>\left(\gamma_{A}+\gamma_{B}\right) \boldsymbol{I}
$$

where $I$ is the identity matrix of corresponding dimensions.

\section{Simulation Results}

The matrices $\boldsymbol{Q}$ and $\boldsymbol{R}$ from (6) are chosen based on the maximum acceptable value of the system's states $\boldsymbol{x}$ and inputs $\boldsymbol{u}$ [11], which scale the elements of the matrices to 1 :

$$
\begin{aligned}
& Q_{i i}=\frac{1}{\text { maximum acceptable value for } x_{i}{ }^{2}} \\
& R_{j j}=\frac{1}{\text { maximum acceptable value for } u_{i}{ }^{2}}
\end{aligned}
$$

For the invariant model in (3), $\boldsymbol{Q}$ and $\boldsymbol{R}$ are:

The function $V(\boldsymbol{x})=\boldsymbol{x}^{T} \boldsymbol{P} \boldsymbol{x}$ is a Lyapunov function for the closed-loop system [7-10], because:

- $\quad V(\boldsymbol{x})>0$, for $\boldsymbol{x} \neq 0$. 


$$
\begin{aligned}
& \begin{array}{lll}
\frac{1}{\mathrm{p}_{\text {in }}{ }^{2}} & 0 & 0
\end{array} \\
& \boldsymbol{Q}=0 \quad \frac{1}{\mathrm{p}_{\text {out }}^{2}} \quad 0 \\
& {\left[\begin{array}{lll}
0 & 0 & \frac{1}{\mathrm{P}_{\mathrm{C}}^{2}}
\end{array}\right]} \\
& \begin{array}{llll}
\frac{1}{\mathrm{~S}_{\mathrm{EGR}}{ }^{2}} & 0 & 0 & 0
\end{array} \\
& \boldsymbol{R}=\begin{array}{llll}
0 & \frac{1}{\mathrm{x}_{\mathrm{VGT}^{2}}} & 0 & 0 \\
& & &
\end{array} \\
& \left\lfloor\begin{array}{cccc}
0 & 0 & \frac{1}{\mathrm{~N}^{2}} & 0 \\
0 & 0 & 0 & \frac{1}{\mathrm{FF}_{\mathrm{F}}^{2}}
\end{array}\right\rfloor
\end{aligned}
$$

and for the reduced invariant model in (4), $\boldsymbol{Q}$ and $\boldsymbol{R}$ are:

$$
\begin{gathered}
\boldsymbol{Q}_{\boldsymbol{r}}=\left[\begin{array}{ccc}
\frac{1}{\mathrm{p}_{\mathrm{in}}^{2}} & 0 & 0 \\
0 & \frac{1}{\mathrm{p}_{\mathrm{out}}^{2}} & 0 \\
0 & 0 & \frac{1}{\mathrm{P}_{\mathrm{C}}^{2}}
\end{array}\right] \\
\boldsymbol{R}_{\boldsymbol{r}}=\left[\begin{array}{cc}
\frac{1}{\mathrm{~S}_{\mathrm{EGR}}{ }^{2}} & 0 \\
0 & \frac{1}{\mathrm{x}_{\mathrm{VTT}^{2}}}
\end{array}\right]
\end{gathered}
$$

We construct $\boldsymbol{Q}_{A}$ and $\boldsymbol{R}_{B}$ as follows [12]:

$$
\begin{gathered}
\boldsymbol{Q}_{A}=\boldsymbol{C}^{T} \boldsymbol{C} \\
\boldsymbol{R}_{B}=q^{2}, q \in\{1,0.1,0.01,0.001\}
\end{gathered}
$$

$\boldsymbol{Q}^{\prime}$ and $\boldsymbol{R}^{\prime}$ are extracted from (11).

\section{A. Invariant state-space model}

The invariant state-space system (3) is represented by the following matrices:

$$
\begin{aligned}
& \boldsymbol{A}=\left[\begin{array}{ccc}
-3.625 & 0 & 373.0841 \\
35.3698 & -93.4776 & 0 \\
0 & 0.026 & -9.0909
\end{array}\right] \\
& \boldsymbol{B}=10^{5}+0.05^{*} \\
& *\left[\begin{array}{cccc}
0.5714 & 0 & -0.000003 & 0 \\
-5.5755 & 0.1020 & 0.00003 & 1.4608 \\
0 & -0.0002 & 0 & 0
\end{array}\right] \\
& \boldsymbol{C}=\left[\begin{array}{ccc}
0 & 0 & 0.0249 \\
1 & 0 & 0
\end{array}\right]
\end{aligned}
$$

The pair $(\boldsymbol{A}, \boldsymbol{B})$ is controllable because the rank of the controllability matrix is 3 , equal to the size of $\boldsymbol{A}$.

Based on (15), $\boldsymbol{Q}$ and $\boldsymbol{R}$ are:

$$
\begin{gathered}
\boldsymbol{Q}=\left[\begin{array}{ccc}
\frac{1}{165^{2}} & 0 & 0 \\
0 & \frac{1}{200^{2}} & 0 \\
0 & 0 & 1
\end{array}\right] \\
\boldsymbol{R}=\left[\begin{array}{cccc}
100^{2} & 0 & 0 & 0 \\
0 & \frac{1}{100^{2}} & 0 & 0 \\
0 & 0 & \frac{1}{1800^{2}} & 0 \\
0 & 0 & 0 & 1
\end{array}\right]
\end{gathered}
$$

The matrices $\boldsymbol{Q}_{A}$ and $\boldsymbol{R}_{B}$ are computed from (17), and $\boldsymbol{Q}^{\prime}$ and $\boldsymbol{R}^{\prime}$ are extracted from (11).

The LQR command $\boldsymbol{K}$ has the value, for $q=0.001$ :

$$
\left.\boldsymbol{K}=\begin{array}{clc}
0.012 & -9.3 * 10^{-5} & 5.5015 \\
0.0107 & 2.73 * 10^{-4} & 5.5022 \\
3.4565 & 0.0863 & 1.78 * 10^{3} \\
L_{1.07 * 10^{-6}} & 3.64 * 10^{-8} & 5.5 * 10^{-4}
\end{array}\right]
$$

Using (12), we obtain $\boldsymbol{\Omega}$, which gives the upper bound of the parameter variations so that the closed-loop system maintains its stability.

$$
\boldsymbol{\Omega}=10^{6} *\left[\begin{array}{ccc}
-4056.4 & 13812 & -292.69 \\
12812 & -3311.7 & 94.155 \\
-292.69 & 94.155 & -5.9927
\end{array}\right]
$$

For $q=0.01$, the corresponding upper bound of the parameter variations, $\boldsymbol{\Omega}$, is:

$$
\boldsymbol{\Omega}=10^{8} *\left[\begin{array}{ccc}
-416.04 & 127.73 & -13.32 \\
127.73 & -43.51 & -9.4513 \\
-13.32 & -9.4513 & -10.453
\end{array}\right]
$$

For $q=0.1, \Omega$, is:

$$
\boldsymbol{\Omega}=10^{11} *\left[\begin{array}{lll}
-1.4553 & -9.1155 & -1.0526 \\
-9.1155 & -1.0828 & -1.0487 \\
-1.0526 & -1.0487 & -1.0497
\end{array}\right]
$$

For $q=1, \boldsymbol{\Omega}$, is:

$$
\boldsymbol{\Omega}=10^{13 *}\left[\begin{array}{lll}
-1.0538 & -1.0484 & -1.0498 \\
-1.0484 & -1.0501 & -1.0498 \\
-1.0498 & -1.0498 & -1.0498
\end{array}\right]
$$

From (21) - (24), we observe that, if $q$ decreases, $\boldsymbol{\Omega}$ decreases.

Fig. 1 plots the closed-loop step response for the LQR control of the invariant model.

For the initial state $x_{0}=\left[\begin{array}{lll}123.17 & 131.37 & 932\end{array}\right]^{\mathrm{T}}$, we have computed the initial condition response of the closedloop system, and plotted the 3-D surface plot for $V(\boldsymbol{x})=\boldsymbol{x}^{T} \boldsymbol{P} \boldsymbol{x}$ (figure 2) and $\dot{V}(\boldsymbol{x})=-\boldsymbol{x}^{T}\left(\boldsymbol{Q}+\boldsymbol{K}^{T} \boldsymbol{R} \boldsymbol{K}\right) \boldsymbol{x}$ (figure 3) on a timespan of $0.5 \mathrm{sec}$. By inspecting these two figures, we observe that $V(\boldsymbol{x})>0$, for $\boldsymbol{x} \neq 0$, and $\dot{V}(\boldsymbol{x})<0$, for $\boldsymbol{x} \neq 0$. Therefore, $V(\boldsymbol{x})$ is a Lyapunov function.

\section{B. Reduced invariant state-space model}

The reduced invariant state-space system (4) is represented by the following matrices:

$$
\begin{gathered}
\boldsymbol{A}^{\prime}=\left[\begin{array}{ccc}
-3.625 & 0 & 373.0841 \\
35.3698 & -93.4776 & 0 \\
0 & 0.026 & -9.0909
\end{array}\right] \\
\boldsymbol{B}^{\prime}=\left[\begin{array}{cc}
57140 & 0 \\
-557550 & 10200 \\
0 & -20
\end{array}\right] \\
\boldsymbol{C}^{\prime}==\left[\begin{array}{lll}
0 & 0 & 0.0249 \\
1 & 0 & 0
\end{array}\right]
\end{gathered}
$$


The pair $\left(\boldsymbol{A}^{\prime}, \boldsymbol{B}^{\prime}\right)$ is controllable because the rank of the controllability matrix is 3 , equal to the size of $\boldsymbol{A}^{\prime}$.

Similar to the iterations in the case of the invariant model, we have:

$$
\begin{gathered}
\boldsymbol{Q}_{\boldsymbol{r}}=\left[\begin{array}{ccc}
\frac{1}{165^{2}} & 0 & 0 \\
0 & \frac{1}{200^{2}} & 0 \\
0 & 0 & 1
\end{array}\right] \\
\boldsymbol{R}_{\boldsymbol{r}}=\left[\begin{array}{cc}
\frac{1}{100^{2}} & 0 \\
0 & \frac{1}{100^{2}}
\end{array}\right]
\end{gathered}
$$

The LQR command $\boldsymbol{K}_{r}$ has the value, for $q=0.001$ :

$$
\boldsymbol{K}_{\boldsymbol{r}}=\left[\begin{array}{ccc}
0.579 & -0.4443 & 24.0738 \\
0.1789 & 0.0273 & -94.9167
\end{array}\right]
$$

Using (12), we obtain $\boldsymbol{\Omega}$, which gives the upper bound of the parameter variations of the reduced model so that the closed-loop system maintains its stability.

$$
\boldsymbol{\Omega}_{r}=\left[\begin{array}{ccc}
-1.46^{*} 10^{16} & 1.37 * 10^{17} & 1.18^{*} 10^{13} \\
1.37 * 10^{17} & -1.27^{*} 10^{18} & -1.1^{*} 10^{14} \\
1.18 * 10^{13} & -1.1 * 10^{14} & -9.45^{*} 10^{9}
\end{array}\right]
$$

For $q=0.01$, the corresponding upper bound of the parameter variations, $\boldsymbol{\Omega}_{\boldsymbol{r}}$, is:

$$
\boldsymbol{\Omega}_{\boldsymbol{r}}=\left[\begin{array}{ccc}
-1.47 * 10^{16} & 1.37 * 10^{17} & 1.18^{*} 10^{13} \\
1.37 * 10^{17} & -1.28 * 10^{18} & -1.1 * 10^{14} \\
1.18 * 10^{13} & -1.1 * 10^{14} & -9.45^{*} 10^{9}
\end{array}\right]
$$

For $q=0.1, \boldsymbol{\Omega}_{\boldsymbol{r}}$ is:

$$
\boldsymbol{\Omega}_{\boldsymbol{r}}=\left[\begin{array}{ccc}
-1.79 * 10^{16} & 1.68 * 10^{17} & 1.18^{*} 10^{13} \\
1.68 * 10^{17} & -1.58 * 10^{18} & -1.1 * 10^{14} \\
1.18 * 10^{13} & -1.1 * 10^{14} & -9.85 * 10^{9}
\end{array}\right]
$$

For $q=1, \boldsymbol{\Omega}_{\boldsymbol{r}}$ is:

$$
\boldsymbol{\Omega}_{\boldsymbol{r}}=\left[\begin{array}{ccc}
-3.41 * 10^{17} & 3.32 * 10^{18} & 1.18^{*} 10^{13} \\
3.32 * 10^{18} & -3.23 * 10^{19} & -8.98 * 10^{13} \\
1.18 * 10^{13} & -8.98 * 10^{13} & -4.94 * 10^{10}
\end{array}\right]
$$

From (28) - (31), we observe that the variations of $q$ have no important effect on $\boldsymbol{\Omega}_{r}$.

Fig. 4 plots the closed-loop step response for the LQR control of the reduced invariant model.

Fig. 5 and fig. 6 plot the 3-D surface for $V(x)$ and $\dot{V}(\boldsymbol{x})$, respectively, for the reduced invariant model, where the initial

\begin{tabular}{|c|c|c|c|c|}
\hline & \multicolumn{4}{|c|}{ LQR step-response characteristics } \\
\hline & $\begin{array}{c}\text { Rise Time } \\
\text { (s) }\end{array}$ & $\begin{array}{l}\text { Settling } \\
\text { Time (s) }\end{array}$ & Overshoot (\%) & $\begin{array}{c}\text { Peak } \\
\text { Amplitude }\end{array}$ \\
\hline$F_{i n}{ }^{a}$ & $7.17 * 10^{-4}$ & 053 & 19.85 & $1.3747 * 10^{-5}$ \\
\hline$p_{i n}{ }^{a}$ & 0.5027 & 0.8931 & 0 & 0.0549 \\
\hline$F_{i n}^{b}$ & 0.001 & 0.0019 & 0.0189 & $2.3748 * 10^{-4}$ \\
\hline$p_{\text {in }}{ }^{b}$ & 0.2282 & 0.3984 & 0 & 15761 \\
\hline
\end{tabular}
condition was set to $x_{0}=\left[\begin{array}{llll}123.17 & 131.37 & 932\end{array}\right]^{\mathrm{T}}$. As we proceeded in the previous case, by inspecting the figures, we can conclude that $V(\boldsymbol{x})$ is a Lyapunov function.

The step-response characteristics for the closed-loop systems are listed in Table I.
TABLE I. LQR STEP-RESPONSE CHARACTERISTICS

\section{Conclusions and Perspectives}

This work investigates the possibility to estimate the maximum domain of model parameter uncertainties for a nonlinear dynamic system. The paper presents an approach on finding the bounds of parameter variations for a state-space system. The gain matrices $\boldsymbol{Q}$ and $\boldsymbol{R}$ in the LQR algorithm are chosen based on the maximum admissible values for the elements of the states vector and control vector, respectively. In the context of robustness analysis, a matrix type bounded uncertain structure has been chosen. The maximum upper bound of parameter uncertainties has been computed so that the closed-loop system remains stable.

Furthermore, this robust analysis and synthesis of a robust controller can be used to optimize a multi-model multicontroller structure based on the maximum admissible uncertainty domain. We can determine the minimum number of commutations among the models on the static characteristic. The problem of maximization of the minimal eigenvalue of $\boldsymbol{\Omega}$ by means of nonlinear techniques, such as reinforcement learning, can be further research.

This proposed solution can be transferred to the improvement of the switching operation control on hybrid engine configurations.

\section{REFERENCES}

[1] R. Patel, and M. Toda, "Quantitative measures of robustness for multivariable systems," IEEE Transactions on Automatic Control, vol. XVII, 1980.

[2] R. Yedavalli, Control design for robust stability in linear regulators: Application to aerospace flight control, Final Report for NASA Langley Research Center, Grant \#NAG-1-578, 1986.

[3] R. K. Yedavalli, "Robust control design for aerospace applications," IEEE Transactions on Aerospace and Electronic Systems, vol. XXV, no. 3, pp. 314-324, May 1989.

[4] C. S. Resnik, A Method for Robust Control of Systems with Parametric Uncertainty Motivated by a Benchmark Example, MS. Department of Aeronautics and Astronautics, MIT, 1991.

[5] L. Yu, G. Chen, and J. Chu, "Optimal guaranteed cost control of linear uncertain systems: LMI approach,” IFAC, 1999.

[6] L. Qiu, and E. J. Davison, "The stability robustness determination of state space models with real unstructured perturbations," Math. Control Signal Systems, vol. IV, pp. 247-267, 1991.

[7] M. Jung, and K. Glover, "Calibratable Linear Parameter-Varying Control of a Turbocharged Diesel Engine," IEEE Transactions on Control Systems Technology, vol. XIV, no. 1, January 2006.

[8] J. B. Heywood, Internal Combustion Engine Fundamentals. McGrawHill, Inc., 1988.

[9] V. Vesely, "Robust control for linear parametric uncertain system with output feedback," IFAC Control Systems Design, Bratislava, Slovak Republic, 2000.

[10] G. Dauphin-Tanguy, L. Foulloy, and D. Popescu, Modelisation, Identification et Commande des Systemes. Editura Academiei Române, București, 2004. 
[11] J. P. Hespanha, Topics in Undergraduate Control Systems Design. 2012.

[12] K. W. Sang, K. H. Wook, and L. H. Joon, "Allowable parameter variations and robustness recovery in LQG regulators," International Journal of Robust and Nonlinear Control, vol. I, p. 33-42, 1991.

[13] B D. Anderson and J.B. Moore, Optimal Control: Linear Quadratic Methods. Prentice Hall, Englewood Cliffs, NJ, 1990.
[14] K J. Astrom and B. Wittemark, Computer Controlled Systems, Theory and Design. Prentice Hall, Englewood Cliffs, NJ, 1998.

[15] M.Dion, D.Popescu, Optimal Control-Optimization Systems. Publishing House Diderot, Paris, 1998.

[16] H. Jerbi, F. Hamidi, S. Olteanu, and D. Popescu, "Lyapunov-based Methods for Maximizing the Domain of Attraction," International Journal of Computers, Communications \& Control (IJCCC), 2020, /doi.org/10.15837/ijccc 202053898
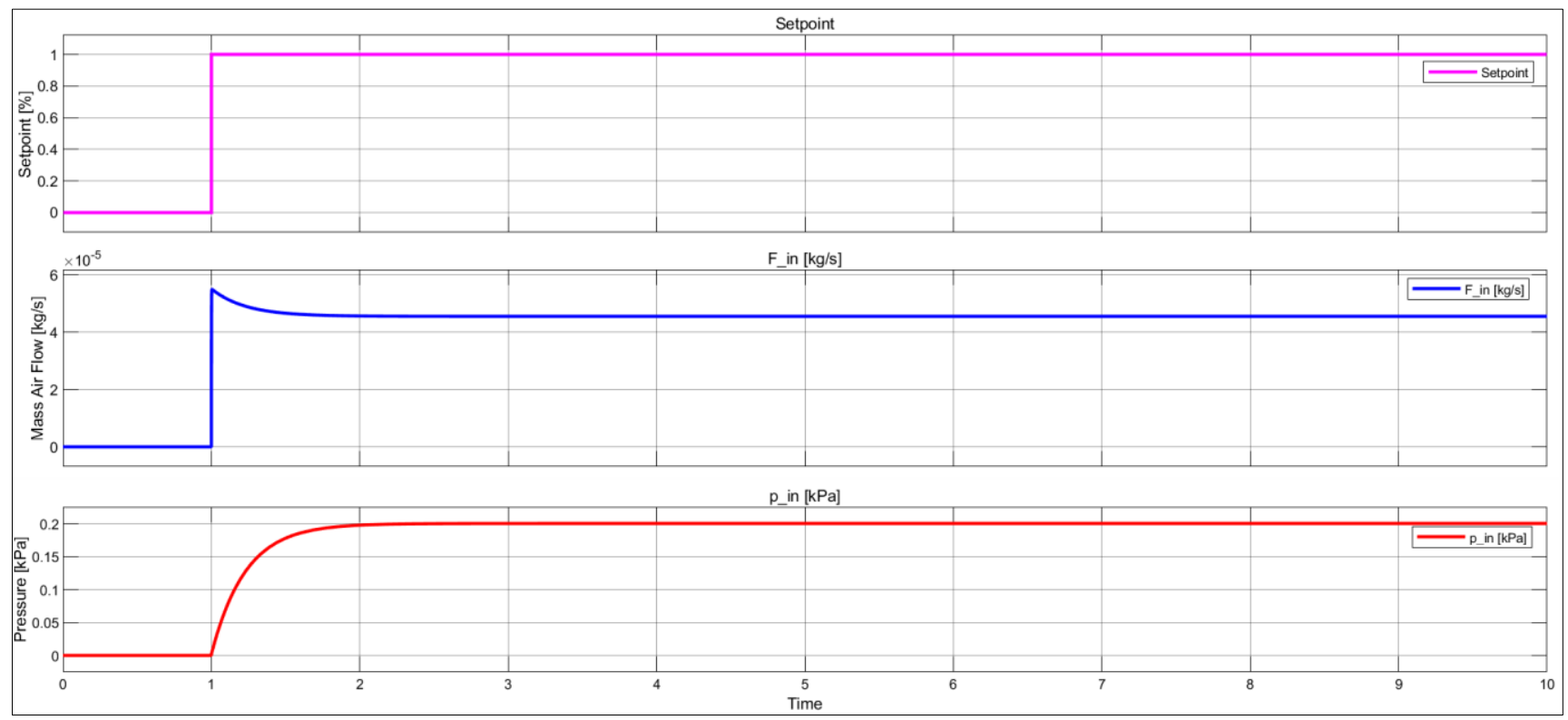

Fig. 1. LQR control step-response for the linearized invariant model

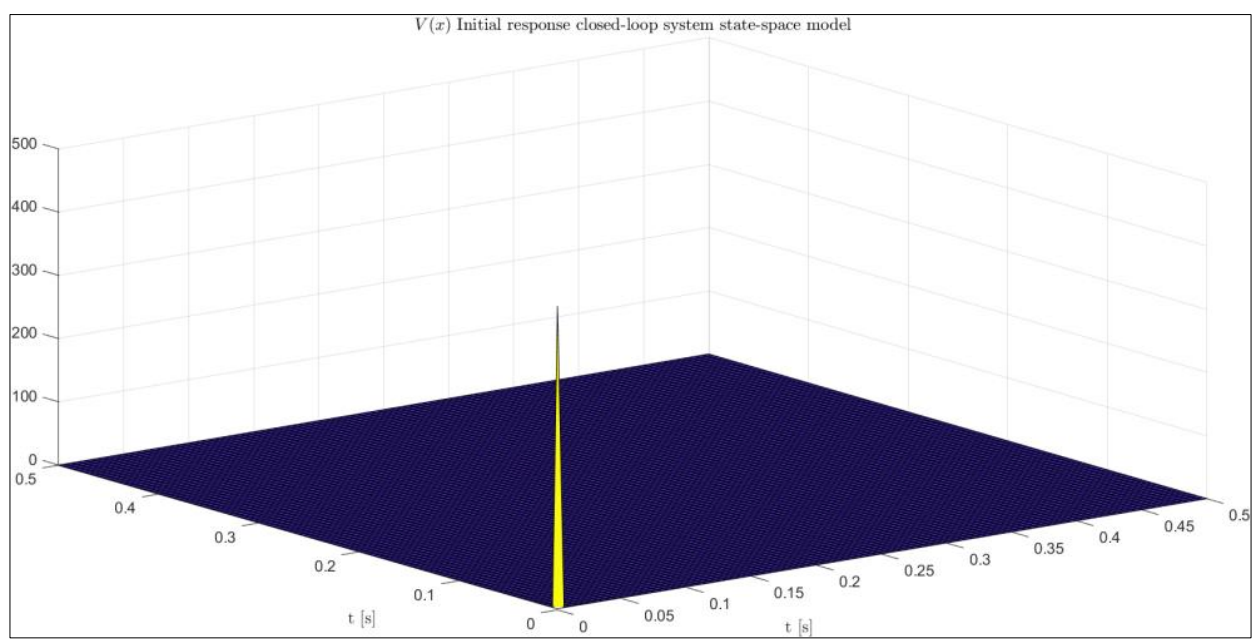

Fig. 2. 3-D surface plot of $\mathrm{V}(\mathrm{x})$ - linearized invariant model

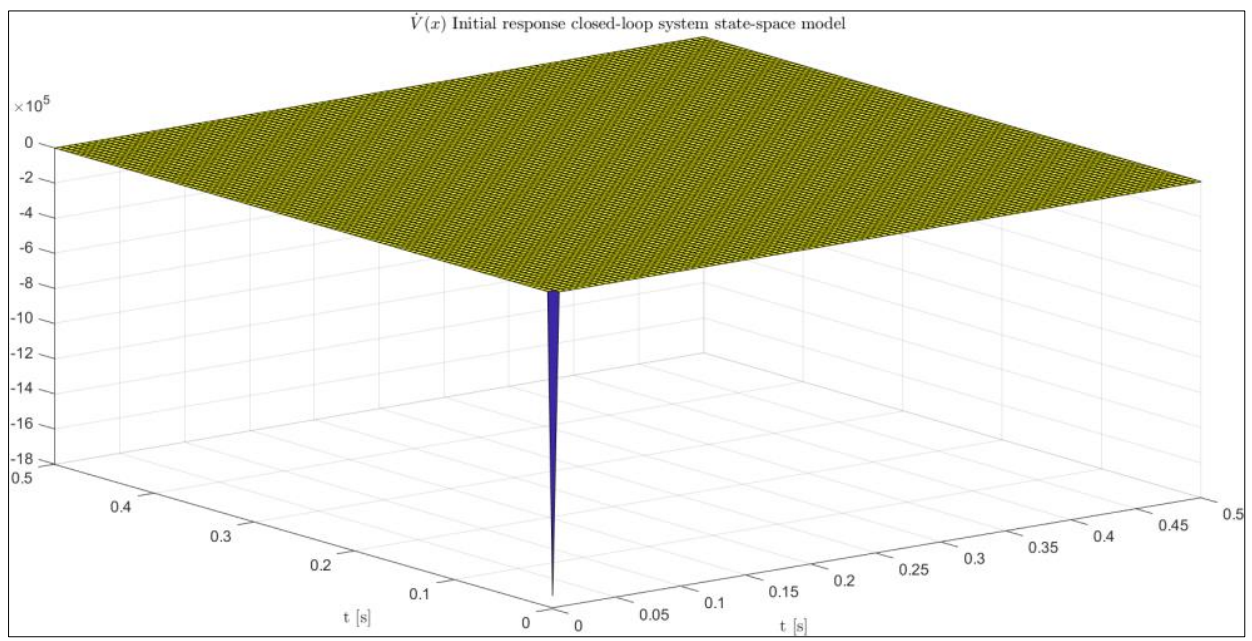

Fig. 3. 3-D surface plot of $\dot{V}(x)$ - linearized invariant model 


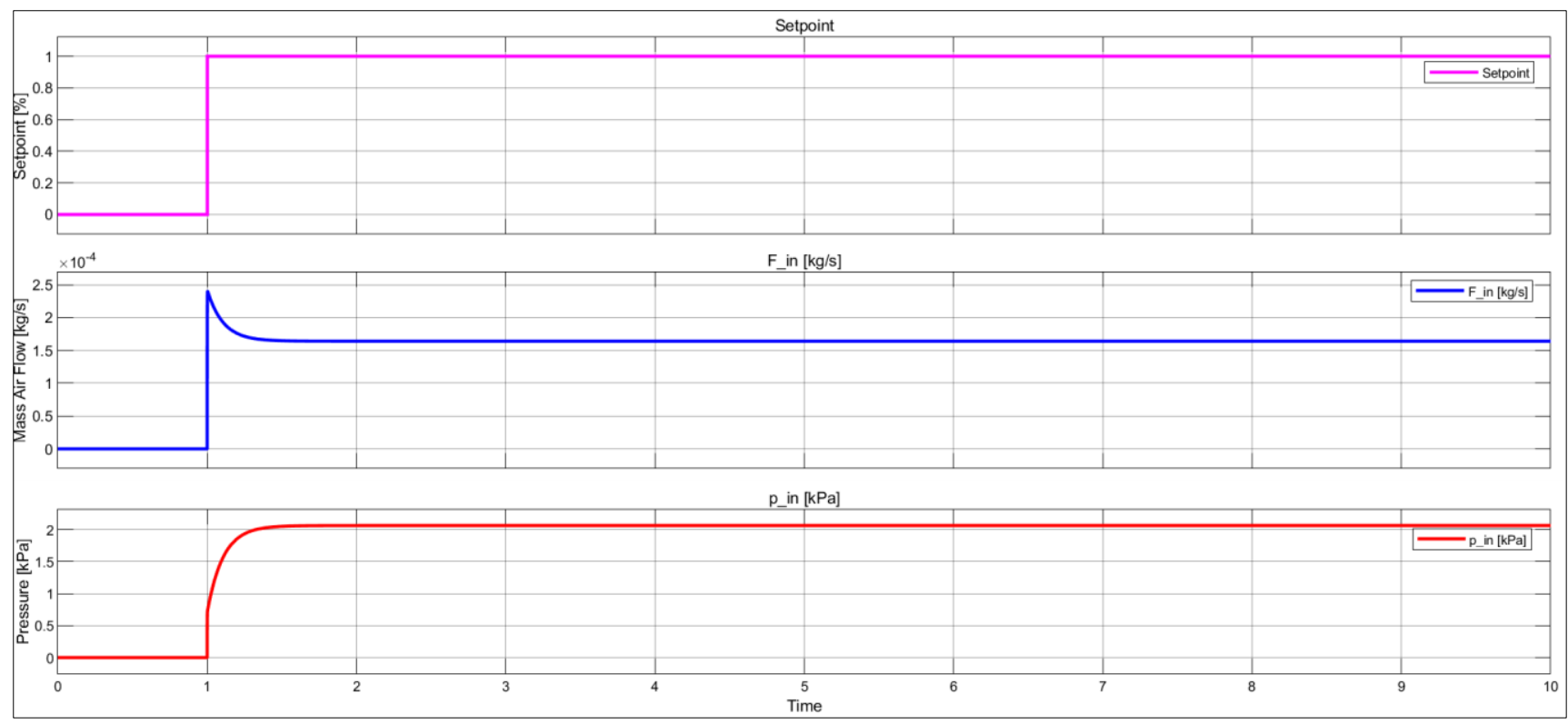

Fig. 4. LQR control step-response for the linearized reduced model

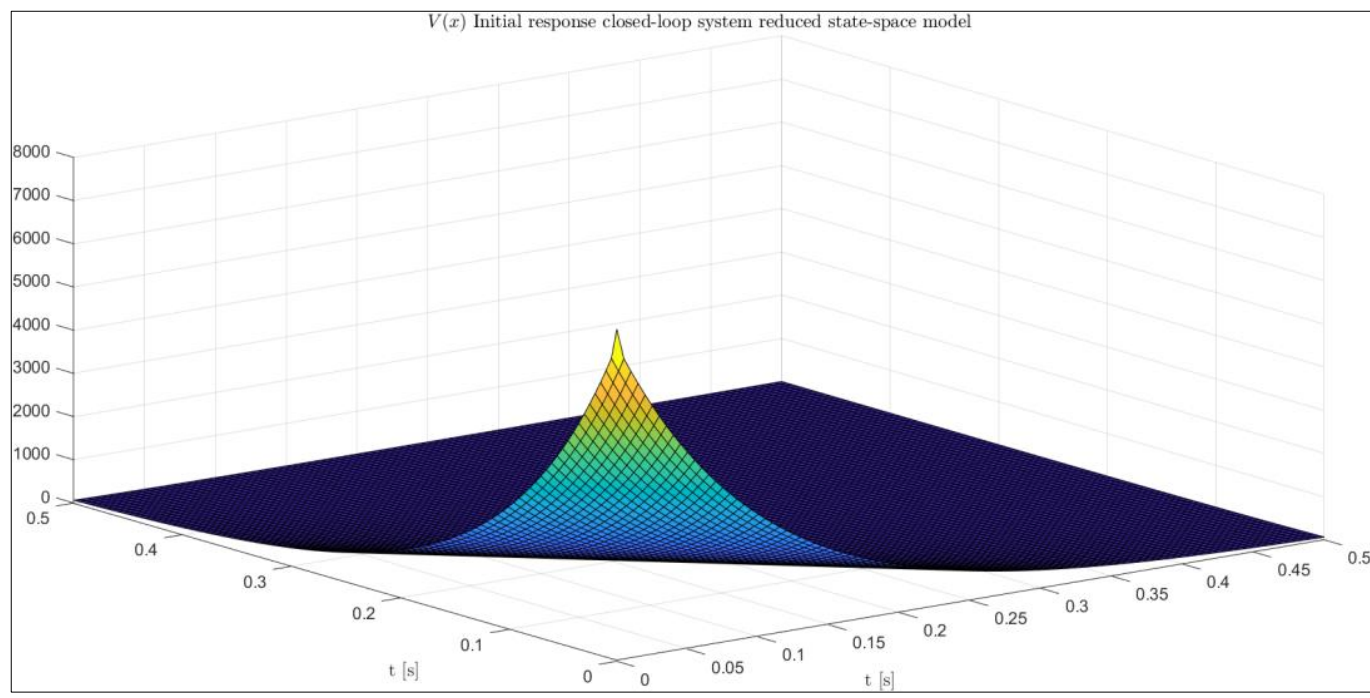

Fig. 5. 3-D surface plot of $V(x)$ - linearized reduced invariant model

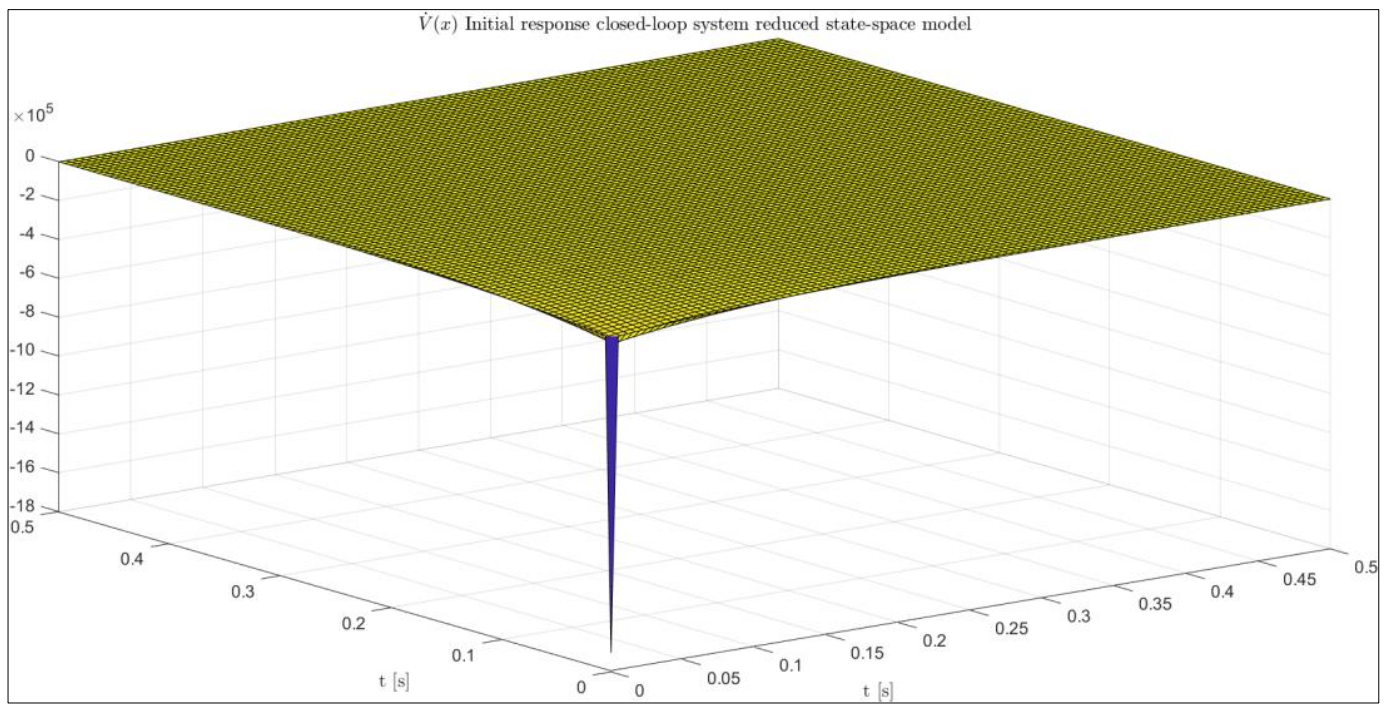

Fig. 6. 3-D surface plot of $\dot{V}(x)$ - linearized reduced invariant model 